\title{
Why Orthopedic Surgery for Elderly Indicates that the Maryland Total Cost of Care Model should be Universally Adopted
}

\author{
Bernard Pettingill, Jr..$^{1^{*}}$ \\ ${ }^{1}$ Consulting Economist, 93 Sandbourne Lane, Palm Beach Gardens, Florida, USA
}

Corresponding Author: Bernard F. Pettingill, Jr., Ph.D. ${ }^{\text {ORCID iD }}$

Address: Consulting Economist, \#93 Sandbourne Lane, Palm Beach Gardens, Florida 33418, USA. Email: biffpett@gmail.com; biffpett@comcast.net

Received date: 06 March 2021; Accepted date: 16 April 2021; Published date: 26 April 2021

Citation: Pettingill B. Why Orthopedic Surgery for Elderly Indicates that the Maryland Total Cost of Care Model should be Universally Adopted. J Health Care and Research. 2021 Apr 26;2(1):63-69.

Copyright (C) 2021 Pettingill B. This is an open-access article distributed under the Creative Commons Attribution License, which permits unrestricted use, distribution, and reproduction in any medium, provided the original work is properly cited.

\begin{abstract}
Arthritis is the disease that kills the fewest but cripples the most. With the aging of the population in the United States and the antiquated DRG reimbursement system for hospital surgical intervention, it is inevitable that the Medicare assistant will bankrupt itself prior to the proposed bankruptcy date of 2026 if changes are not made. It may change would be to insist that the system in Maryland for reimbursement to hospitals for essential joint replacement surgery of the elderly be adapted nationwide.
\end{abstract}

\section{Keywords}

Arthritis, Bankruptcy, Medicare, Diagnostic Related Groups, Reimbursement, Government Support, Joint Replacements

Medicaid expenditures are driven by a variety of factors, including the demand for care, the complexity of medical services provided, medical inflation, and life expectancy. The Medicare program has two separate trust funds - the Hospital Insurance (HI) Trust Fund and the Supplementary Medical Insurance (SMI) Trust Fund. Under the Hospital Insurance Trust, payroll taxes from workers and their employers go towards paying for the Part A benefits for today's Medicare beneficiaries. In 2019, Medicare provided benefits to over 60 million elderly patients at an estimated cost of $\$ 796$ billion [1].

While excluding the significant decrease in payroll taxes during the COVID-19 pandemic, the latest 2020 projections calculate Medicare Hospital Trust insolvency by 2026 [2]. The 2020 report declared that funds would be sufficient to pay for only 90 percent of Part A expenses at the time of this writing.

Since inception, the Hospital Insurance Trust has never been insolvent, because there are no provisions in the Social Security Act that govern what would happen if insolvency were to occur. Ten of the last twelve years have witnessed expenditure outflows outpacing the Hospital Insurance Trust inflows, resulting in total Medicare spending obligations outpacing the increasing demands on the federal budget, as the number of elderly beneficiaries and the per capita health care costs continue to grow [2].

One of the principal goals of the following study is to determine how elderly patients, who often suffer from acute stages of arthritis and other orthopedic diseases, 
due in part to wear and tear, can continue to demand surgical intervention, in particular joint replacement surgery. Arthritis has been described as the disease that kills the fewest but cripples the most. With that in mind, the hospital systems ability to absorb the ever increasing number of elderly patients who demand joint replacement surgeries will continue to outstrip supply. The principal author of this study completed his $\mathrm{PhD}$ dissertation at the University of Manchester in 1977 by measuring the cost-benefit analysis of the treatment of chronic rheumatoid arthritis in Great Britain. Therefore, the author of this study aims to show the only reasonable method of payment for the imminent immeasurable demand for treatment for the elderly for age related diseases such as joint replacement surgery [3].

A recent Journal of Rheumatology article projects Medicare will finance approximately 2.67 million joint replacement surgeries by 2035, plus an additional 2.35 million joint replacement surgeries by the year 2040 [4]. The author believes that the current nationwide Diagnostic Related Groups (DRGs) system that helps determine how much Medicare pays the hospital for each "product" needs to be phased out as soon as possible. Our research shows that prior to Medicare implementing the DRGs payment system, Maryland proved that their total cost model of state-wide rewards and penalties compensated "efficient and effective" hospitals, providing care as defined by metrics set up by the Health Services Cost Review Commission (HSCRC). The Maryland legislature granted this independent government agency the broad powers to insulate the HSCRC from conflicts of interests, regulatory capture, and political meddling in the long term. In exchange, the HSCRC had the freedom to design a system that must deliver on three areas: cost reduction of hospital services, health improvement for all Maryland residents, and quality of life care improvements.

Since inception of the HSCRC, all stakeholders are legally required to comply with robust auditing and data-submission requirements that allow the agency to collect data on the costs, patient volume, and financial condition of all inpatient, hospital-based outpatient, and emergency services in Maryland. This level of transparency allows the agency to set prices for hospital services, and hospitals must obey because it is Maryland law. Because of this methodology, HSCRCapproved average Maryland hospital markups ranged from 18 percent in 1980 to only 22 percent in 2008 . During that same period, the average hospital markup nationally skyrocketed from 20 percent in 1980 to more than 187 percent in 2008 [5]. This strong evidence is the primary reason why the HSCRC has continued to receive a federal waiver from the Centers for Medicare and Medicaid Services, which requires both Medicare and Medicaid to pay the HSCRCapproved rates statewide. No discounts are given because of volume, nor any shifting of costs to other payers. There is a mandate: same price for the same service at the same hospital, no exceptions. Adjustments for uncompensated medical care are automatically bundled into the HSCRC-approved rates, as thus, this financial burden is shared by all hospitals in Maryland.

This article explores the important milestones taken by the state of Maryland and how the lessons learned are responsible for the impressive results of their program today. This author believes that by applying the Maryland Total Cost of Care Model (Maryland TCOC Model) nationwide will yield financial savings of at least \$227 billion by 2035, plus another \$280 billion by 2040, exclusively from joint replacement surgeries reimbursed at HSCRC-approved rates and not any other method.

\section{Joint Replacement Surgery Statistics}

A study by the Peterson-KFF Health System Tracker concluded that prices vary drastically depending on the location of hospital services [6]. In this study, the price refers to the allowed charges, which is the amount paid including markup and cost-shifting under the plan for a given service, including both the plan's and the enrollee's share, but excluding any balance billing that may occur if the providing clinicians were out-ofnetwork.

For joint replacement, the average 2018 price in the New York metro area $(\$ 58,193)$ was more than double the average price in the Baltimore, Maryland area $(\$ 23,170)$ for similar if not identical surgeries. Under 
the DRGs that help determine how much Medicare pays the hospital for each "product," the New York metro area and the Baltimore region offer identical "product" to clinically "similar patients" who use the same level or similar level of hospital resources. The only difference between the two states is the waiver of federal law that requires Medicare to pay hospitals in the Maryland region according to HSCRC-approved rates. In other words, average prices for New York metro area come exclusively from DRGs and the average prices for the Maryland region come exclusively from HSCRC-approved rates.

The author has performed an historical study of the Consumer Price Index (CPI) for medical care over the last 50 years [7]. Because excessive hospital markups continue unconstrained, the category of hospital services had the highest exponential growth in the last twenty plus years. The author believes that both Medicare and Medicaid will continue to bear most of the financial burden from forthcoming medical inflation in the coming decades, as American Baby Boomers continue to age and live longer, but suffer the consequences of age-related diseases like arthritis. The author fears that retaining the status quo will push these programs closer to bankruptcy and at a faster pace. The author believes that the current nationwide Diagnostic Related Groups (DRGs) system that determines how much Medicare pays the hospital for each "product" needs to be phased out as soon as possible. Instead, the author favors focusing all resources towards a nationwide implementation of the Maryland Total Cost of Care Model (Maryland TCOC Model).

To explain this need, an analysis of just two surgeries in high demand by the elderly point out the following savings by applying the Maryland Total Cost of Care Model nationwide:

- The average 2018 price in the New York metro area $(\$ 58,193)$ will grow exponentially to equal $\$ 141,371$ by 2035 , and over $\$ 198,672$ in 2040 , respectively [8].

- The average 2018 price in the Baltimore, Maryland region $(\$ 23,170)$ will grow exponentially to equate to only $\$ 56,288$ by 2035 and $\$ 79,103$ in 2040, respectively [9].

Joint replacement includes both knee replacements and hip replacements. In medical terms, these are known as total knee arthroplasty (TKA) and total hip arthroplasty (THA) surgeries. According to one reliable source that tracks these surgeries, i.e., the Journal of Rheumatology, the future projections are as follows [4].

- Total Knee Arthroplasty (TKA): 2.6 million TKAs by 2035; 3.4 million TKAs by 2040

- TKAs covered by Medicare: 1.9 million TKAs by 2035; 2.3 million TKAs by 2040

- Total Hip Arthroplasty (THA): 1.1 million THAs by $2035 ; 1.4$ million THAs by 2040

- THAs covered by Medicare: 770,000 THAs by 2035; 951,000 THAs by 2040

Because Medicare will cover approximately 2.67 million joint replacements by 2035, multiplied by the approximate financial savings of at least $\$ 85$,ooo per surgery by 2035. The author has determined that Medicare will save over $\$ 227$ billion by reimbursing hospitals at the HSCRC-approved rate schedule instead of the Medicare DRGs model rates [10].

In addition, Medicare will cover approximately 2.35 million joint replacements surgeries by 2040, multiplied by the approximate financial savings of $\$ 119,000$ per surgery in 2040. The author believes that Medicare will save over $\$ 280$ billion by reimbursing hospitals at HSCRC-approved rates, instead of the Medicare DRGs model rates [11].

\section{What is the Maryland Model (1971-2013)}

Historically, had the nation's hospital costs grown at the state of Maryland's rate of growth, the cumulative savings would have exceeded $\$ 1.8$ trillion between 1976 and 2007 [5], nearly $\$ 2.3$ trillion in 2021 dollars. This savings includes the "reasonable costs" of uncompensated care in the Maryland payment rates that grew from \$36 million in 1977 to $\$ 927$ million in 2007, shared across all hospitals statewide. Additionally, the American Hospital Association data illustrates that the average hospital markup of charges over costs nationally had increased from 20 percent in 
1980 to more than 187 percent by 2008. During the same period, the HSCRC-approved Maryland average hospital markups ranged from 18 percent in 1980 to only 22 percent by 2008 [5]. A former executive direction of the HSCRC boiled down this impressive success to three main reasons.

First, uniform approach. The HSCRC system ties all the stakeholders together under a common set of rules; it provides clear mandates and allows for flexibility of design. Since 1971, the HSCRC collected data on the costs, patient volume, and financial condition of hospitals, as well as patient-level inpatient and outpatient data. Their innovation was creating robust auditing and compliance to ensure pricing and datasubmission requirements. Today, these detailed databases monitor forty-seven general acute, three specialties, and three private psychiatric hospitals in Maryland. The uniform approach, coupled with strong incentives for acting quickly, contributes to the commission's cooperative rule making among Medicare, Medicaid, and commercial players.

Second, insulated from conflicts of interests. All parties are accountable to the public. Harold Cohen, the founding executive director of the HSCRC who worked for 38 years in the system, noted that the HSCRC had political, legal, and budgetary independence as a freestanding agency; therefore, insulating its work from conflicts of interests, regulatory impositions, and political meddling. This freedom allows the HSCRC to solicit input from all interested parties in order to work in the broad "public interest." From an operational viewpoint, the agency remains governed by seven volunteer commissioners appointed by the governor for four-year staggered terms. Commissioners are recruited from an array of health care backgrounds and expertise, but no more than three can have provider affiliations. Day-to-day operations are performed by fewer than 30 full-time staff with expertise in accounting, data systems, hospital financing, and policy development. Its annual budget is funded through user fees and is not subject to the constraints of Maryland's general fund [5].

Third, flexible approach. Eugene Feinblatt wrote the law that created the Health Services Cost Review
Commission (HSCRC), giving broad responsibilities regarding the public disclosure of hospital financial and trustee relationships [12]. At the time, the Maryland legislature envisioned an independent government agency to create a system that would provide financial stability and focus on constraining hospital costs, rather than controlling hospital profits. These broad powers would assign the everyday details up to the HSCRC, as it adapted this rate system to the changing dynamics of the times [13]. The HSCRC provided consistent payment incentives and remained laser-focused on cost control via overall hospital budget constraints. Hospital managers had the freedom and flexibility to allocate resources towards boosting operational improvements, rewarding the more "efficient and effective" hospitals with resulting savings, and directly boosting their financial solvency. This methodology aligned statewide rewards and penalties in the direction of the financial solvency of the "efficient and effective" hospitals.

\section{What is the HSCRC's Regulatory Approach}

With its innovative database, the HSCRC now had a tool to monitor hospitals providing "efficient and effective" care (as defined by the HSCRC) to operate on a solvency basis alone. There were no discounts to specific payers, and the financial burden uncompensated care is shared by all providers. The HSCRC developed clear, attainable, and strong financial incentives for hospitals to improve their operations in defined areas, and because the hospitals could keep all the savings from the operational improvements, the hospitals constantly worked on improving their financial health and solvency.

Except for Maryland, the Medicare DRGs tend to make hospitals in competitive markets earn profits by the application of artificially high markups and shifting costs to other payers. The HSCRC enforces a true "allpayer" model whereby the same services at the same hospital carry the same price. Because of this standardization, there are no discounts to specific payers. Additionally, the HSCRC has always enforced this "no cost-shifting" policy. As a result, Maryland hospitals have remained competitive by managing costs and utilization. 
The HSCRC constraints overall hospital budgets by giving hospital managers maximum flexibility to allocate resources to control hospital costs. At its own discretion as an independent government agency, the HSCRC has a long-term focus for policy goals over time and avoids wasting resources on major shortterm disruptions in the hospital delivery system.

The HSCRC does not control hospital profits because each hospital is rewarded internally by keeping their savings by efficient management. Outside of Maryland, cost-based payment systems exist in all states. In a system with 100 percent prospective payment, hospitals are completely at risk regarding their spending decisions. The Medicare DRGs focus on a "per case" payment system that does not measure how much time passes between the start and finish of each hospital admission. The author believes that the main disadvantage of the DRGs is their incorrect assumption that all patents, regardless of age, will demand the "same level of hospital resources" based on a composition of DRGs, even if patients are clinically similar to receive the same "product" at the same hospital. The length of time between the start and finish of each patient hospital stay per DRG directly impacts hospital resources and its operating costs in each case.

Maryland does not use a "per case" system, but a superior "service-specific unit rate" as the basis of payment. For example, joint replacement surgeries include by knee replacements (total knee arthroplasty - TKA) and hip replacements (total hip arthroplasty THA) surgeries. By using MINUTES as the "servicespecific unit rate," the HSCRC measures operating room charges in a reasonable, equitable and transparent way. These "service-specific unit rates" include costs, markups for services provided, and adjustments for all hospitals sharing the financial burden of uncompensated care.

One former executive director of the HSCRC commented recently that hospital revenues in Maryland are controlled through the use of per case constraints (case-mix adjustments using all patient refined diagnosis-related groups [APR-DRGs] for inpatient and ambulatory patient groups [APGs] for outpatient services). Like the Medicare system, it was developed to control utilization per encounter and adjusted for case-mix. Unlike the Medicare system, the reward and penalties for performance are aggregated through adjustments to overall hospital-approved revenues each year. This system has important payerequity advantages over a "per case" system because it reflects actual resources used. It also aligns the incentives across payers and hospitals. These and other rate mechanisms were developed to support models of managed care in the state of Maryland.

The HSCRC system uses a "Federal Inflation Adjustment System" implemented in 1977. It is like Medicare in adjusting for input-price inflation, productivity, and new technology factors, but the Maryland advantage is that the HSCRC includes rewards and penalties based on hospital-to-hospital comparisons of standardized charges per hospital admission.

The standard measures of quality of care in a hospital setting have always been extended life expectancy and reduce morbidity. But quality of hospital care inpatient treatment has always been difficult to measure and has normally been done on a subjective, Likert-type scaling system in which patients evaluate their care and treatment. With DRG induced payment, together with hospital competition for competitive pricing and ultimately profit, the DRG system is doomed to failure. Granted, a Maryland based system will save billions in the long run, but there is no simple method of determining whether or not cost savings equally to diminished quality of care. That is the subject for another entirely different study.

The creation of the HSCRC as an independent agency by the legislature was developed to find the best solution for the problem of financing the cost of uncompensated care in a reasonable, equitable, and transparent way. In 2002, the HSCRC enforced an assessment on hospital rates that subsidized premiums to 17,000 medically uninsurable individuals. That money went to Maryland's "high-risk" insurance pool. During the financial crisis of 2008, the HSCFC added an "Uncompensated Care Pooling" mechanism that would increase the fairness of financing 
uncompensated care by dividing the financial burden across all hospitals. In conclusion, the Maryland system must be adopted nationwide to avoid the train wreck that is inevitably waiting to happen.

\section{The Success of the Maryland Global Budget Model (2014-2018): Results of Policy}

Cost containment in the five years between 2014 and 2018 surpassed its initial targets in the following ways [14].

1. Maryland maintained the 2nd lowest nationwide Employer-Sponsored Healthcare Spending, for both inpatient and outpatient services.

2. Maryland targeted to save the federal Medicare program at least \$330 million on hospital care over five years. Instead, Maryland surpassed the goal and Medicare saved \$1,421 million over these five years.

3. Maryland agreed to shift from a "per case" rate system, transitioning at least 80 percent of hospital revenue, to population-based "global budgets" by 2018. Actual results were 95 percent of all hospital revenue came from the "global budgets" over these five years. The remaining 5 percent excluded from the "global budget revenue" accounts for drug costs, which are funded based on volume.

4. All-Payer hospital spending growth per capita targeted nearly 20 percent cumulative increase over five years. Instead, the actual results were 10 percent cumulative increase over five years, i.e., less than half.

5. Maryland's hospital readmission rate for Medicare fee-for-service beneficiaries were required to be at or below the national admission rate. Over five years, this metric went from 1.22 percentage points higher than the national average to 0.05 percentage points lower than the national average for Medicare patients.

6. Maryland targeted a 30 percent reduction in All-Payer Potentially Preventable Complications (All-Payer PPCs). This metric decreased 51 percent over these five years, an astonishing improvement considering the rest of the nation's hospitals following the DRG system.

Indeed, the federal government cannot continue to utilize the DRG system to reimburse hospitals for similarly situated, invasive type treatments like orthopedic surgeries described above. One of the last measures of the Trump administration before he left office was to implement transparency rules for 500 of the most "shop bubble" hospital services by the year 2023. Unfortunately, this rule may never be enacted or enforced. The only method, in this author's opinion, to save Medicare from meeting even earlier bankruptcy than is described above, is to force hospitals to adopt the Maryland total cost care model system. Without that system in place in the next few years, hospitals will be forced to ration inpatient catastrophic invasive surgeries due to age-related arthritic problems. Only when excessive hospital markups, favorable discounts, and cost shifting is reduced or totally eliminated, will transparency rules regarding pricing of inpatient care become effective enough to save the system. The Maryland total cost model has been proven to be an effective and efficient method of successfully maintaining minimal hospital cost inflation for similarly situated patients.

\section{Competing Interests}

The author has read and approved the final version of the manuscript. The author has no conflicts of interest to declare.

\section{References}

[1] The boards of trustees, federal hospital insurance and federal supplementary medical insurance trust funds. The 2020 annual report of the boards of trustees of the federal hospital insurance and federal supplementary medical insurance trust funds. United States: CMS Gov; 2020 Apr 22. Table II.B1.-Medicare Data for Calendar Year 2019. Available from: https://www.cms.gov/files/document/2020-medicaretrustees-report.pdf

[2] Congressional Research Service. Medicare: Insolvency Projections. United States; 2020 May 19. Available from:

https://fas.org/sgp/crs/misc/RS20946.pdf

[3] Bernard F. Pettingill, Jr. Cost-Effectiveness Analysis of the Treatment of Rheumatoid Arthritis in Great 
Britain, a Comparison of Five Hospitals. Department of Economics and Social Administration, University of Manchester; 1977 March.

[4] Singh JA, Yu S, Chen L, Cleveland JD. Rates of Total Joint Replacement in the United States: Future Projections to 2020-2040 Using the National Inpatient Sample. J Rheumatol. 2019 Sep;46(9):1134-40. [PMID: 30988126]

[5] Murray R. Setting hospital rates to control costs and boost quality: the Maryland experience. Health Aff (Millwood). 2009 Sep-Oct;28(5):1395-405. [PMID: 19738257]

[6] Kurani N, Rae M, Pollitz K, Amin K, Cox C. Price Transparency and Variation in U.S. Health Services. United States: Peterson-KFF Health System Tracker; 2021 Jan 13. Available from:

https://www.healthsystemtracker.org/brief/pricetransparency-and-variation-in-u-s-health-services/

[7] Bernard P. CPI-ACT-HX: Consumer Price Index All Urban Consumers. United States: US Bureau of Labor Statistics; 2021 Mar 2. Available from:

http://data.bls.gov/pdq/querytool.jsp? survey=cu

[8] Historical rate of increase for surgical intervention for 17 years is $5.36 \%$ annually.

[9] Historical rate of increase for surgical intervention for 22 years is $5.74 \%$ annually.

[10] In 2035, New York price $(\$ 141,371)$ minus
Maryland price $(\$ 56,288)$ equals $\$ 85,083$ in savings per surgery.

[11] In 2040, New York price $(\$ 198,672)$ minus Maryland price $(\$ 79,103)$ equals $\$ 119,569$ in savings per surgery.

[12] Rafael A. Eugene Feinblatt, 78, Key City Figure, Dies Advisor to Mayors Played Major Role in Baltimore Revival. United States: Baltimoresun; 2018 Oct 12. Available from: www.baltimoresun.com/news/bs-xpm-1998-07-171998198068-story.html

[13] Larry W. Richard J. Davidson in First Person: An Oral History. United States: American Hospital Association Center for Hospital and Healthcare Administration History and Health Research \& Educational Trust; 2010 [cited 2021 Mar 02]. Available from:

https://www.aha.org/system/files/2018-03/richarddavidson-2010.pdf

[14] Maryland Hospital Association. Maryland AllPayer Model Performance: Years 1 Through 5 (CY 2014 - CY 2018). United States: MHA Online; 2018 [Cited 2021 Mar 02]. Available from:

https://www.mhaonline.org/docs/defaultsource/transforming-health-care/maryland-modeldashboard/medicare-waiver-performance(final).pdf?sfvrsn=cf79d6od_18 